\title{
JUVENTUDE, TRABALHO E ESCOLA: ELEMENTOS PARA ANÁLISE DE UMA POSIÇÃO SOCIAL FECUNDA
}

\author{
Mônica Peregrino*
}

\begin{abstract}
RESUMO: No quadro da retração estrutural do número de postos de trabalho e da expansão da escolarização, a juventude emerge como um problema social. A extensão do tempo de convivência entre trabalho e escola é uma das bases da questão. No Brasil, o problema entra em cena a partir da década de 1990 com contornos próprios: aqui é a expansão da escola que permite a convivência desta instituição para com aquela que se apresentava, até então como umas das mais importantes instituições de socialização dos jovens do país: o trabalho. O presente artigo se propõe a analisar a questão, no quadro particular da situação brasileira, a partir de dois movimentos: primeiramente, pela constituição da noção de juventude como posição social e analítica desta sociedade; em segundo lugar, pelo uso da "ferramenta" na análise da importância relativa da escola e do trabalho na transição do jovem para a vida adulta, a partir do estudo do caso particular de conjunto de jovens de periferia do Rio de Janeiro.
\end{abstract}

Palavras-chave: Juventude. Desigualdades sociais. Processos de socialização.

YOUTH, WORK AND SCHOOL:

ELEMENTS TO ANALYZE A FERTILE SOCIAL POSITION

ABSTRACT: As part of the structural decline in the number of jobs and the expansion of schooling, youth emerges as a social problem. The length of the work-school coexistence is one of the bases of that matter. In Brazil, the problem emerged in the 1990s with singular

Doutora em Educação e professora adjunta no Programa de Pós-Graduação em Educação, Cultura e Comunicação nas Periferias Urbanas da Universidade do Estado do Rio de Janeiro (UERJ). E-mail: mônica_peregrino@yahoo.com.br 
contours. In this country, the very expansion of schooling allowed youth to combine their recent school experiences with work, the most important institution of socialization of young people until then. This paper analyzes this issue based on two movements: through the constitution of the notion of youth as a social and analytical position in the Brazilian society and, secondly, by the use of the "tool" to analyze the relative importance of school and work in the transition from youth to adulthood, based on the case study of a specific group of youths from the periphery of Rio de Janeiro

Key words: Youth. Social inequalities. Socialization processes.

\section{Introdução}

$s$ estudos sobre juventude, desde as vertentes fundadas no estudo das gerações, vem buscando entender não só os elementos que agregam os jovens (em tempos e espaços determinados), mas também os inúmeros fatores envolvidos nesta "agregação" - as instituições partícipes, as relações com as geraçôes que as antecedem, os mecanismos que envolvem sua autonomia ou tutela, os conjuntos de valores produzidos, as expressões culturais construídas .

Por outro lado, temos também os estudos que, sem diminuir a importância de entender as singularidades que demarcam a "juventude", centram suas questóes no entendimento das muitas e desiguais formas de vivê-la em determinado espaço/tempo.

Em qualquer dos casos, estudar a juventude implica o acesso a algumas das dinâmicas fundamentais para a compreensão das sociedades contemporâneas. Estudar as gerações é desvendar os mecanismos pelos quais o poder é "transmitido" de uma geração a outra, com todas as particularidades e singularidades que envolvem tal transmissão em formações sociais específicas. Estudar as desigualdades e diferenças não só na maneira de ser jovem, mas também nas possibilidades de reivindicar e, portanto, de exercer a própria juventude abre-nos a possibilidade de entendermos o grau e a amplitude dos investimentos feitos por uma sociedade no conjunto dos sujeitos que prefiguram o seu futuro.

Em qualquer dos casos, estudar a juventude é tomá-la como ferramenta de análise da sociedade, inquirindo suas características, singularidades, seus limites e suas possibilidades, tomando o período de 
transição entre a infância e a vida adulta como posição privilegiada de observação de uma dinâmica sempre complexa.

O presente artigo se propõe a analisar a questão, no quadro particular da situação brasileira, a partir de dois movimentos: primeiramente, pela constituição da noção de juventude como posição social e analítica desta sociedade; em segundo lugar, pelo uso da "ferramenta" na análise da importância relativa da escola e do trabalho na transição do jovem para a vida adulta, a partir do estudo do caso particular de conjunto de jovens de periferia do Rio de Janeiro

Juventude como posição social desigual/juventude como ferramenta analítica

Para Mannheim (1968), a juventude é a reserva vital das sociedades modernas; espécie de acúmulo energético, físico e mental somente posto em evidência em circunstâncias singulares, especialmente em situaçôes que reivindicam necessidade de ajustamento a mudanças drásticas e imediatas. Nesse sentido, juventude é, para o autor, agente revitalizante da sociedade.

Para nossa apreciação, não é tanto a maior sensação de conflito da juventude que interessa, mas outra faceta da mesma situação com que ela se depara: no contexto de nossos problemas, o fato relevante é que a juventude chega aos conflitos de nossa sociedade moderna vinda de fora. E é esse fato que faz da juventude o pioneiro predestinado de qualquer mudança da sociedade. (Mannheim, 1968, p. 74. Grifo nosso)

Para o autor, o que torna os jovens um conjunto tão singular é, ao mesmo tempo, o fato destes não aceitarem como natural a ordem consagrada e nem possuírem interesses adquiridos de ordem econômica ou espiritual. Aqui, a juventude é agente revitalizador porque não está ainda completamente enredada no status quo da ordem social.

Trocando em miúdos, o que interessa neste caso é a marginalidade da situação juvenil na sociedade. É essa liminaridade de condição que interessa ao autor. Para Mannheim, não só a posição de "estranho" é fator mais importante do que a efervescência biológica para explicar a mutabilidade e a receptividade do jovem ao "novo", mas também essa disposição é coincidente para com as atitudes de outras 
Juventude, trabalho e escola: elementos para análise de uma posição social fecunda

populações lançadas em situação de marginalidade social. Finalmente, essa potencialidade é sempre condicionada pela configuração social, histórica, política e econômica.

Para Mannheim (op. cit.), portanto, é a posição marginal da juventude nas sociedades modernas que a agrega como grupo social. É aquilo que a faz suscetível ao estranhamento das normas e dos valores sociais e, ao mesmo tempo, que a predispõe à mudança. $\mathrm{O}$ autor, porém, dá pouca atenção às clivagens que dividem o grupo.

Bourdieu (1983), por outro lado, instigando-nos a pensar em que medida "juventude seria apenas uma palavra", chama nossa atenção para a aparente arbitrariedade das classificaçóes etárias, mostrando-nos que, se por um lado, "classificar" é condicionar aquilo que foi "classificado" a um "lugar" social, por outro lado, a constituição de "homogêneos” sociais (como as classificações etárias, por exemplo) requer, sempre, um tanto de manipulação, principalmente em relação à "seleção" dos critérios de classificação.

Especialmente quanto à noção de juventude, o autor francês nos chama a atenção para o fato de que ao tomarmos os jovens como uma unidade social, grupo dotado de interesses comuns, corremos, para além de todos os outros, o risco de perdermos de vista as diferenças e desigualdades que marcam as muitas formas de exercer este período da vida, marcado por significativas diferenças relativas às condições de existência, às relaçóes mantidas para com o trabalho e ao orçamento do tempo, nas vidas dos sujeitos.

Comparando os estilos de vida dos jovens que já trabalham e dos adolescentes que só estudam, o autor nos mostra que se,

(...) de um lado, [temos] as coerçôes do universo econômico real, apenas atenuadas pela solidariedade familiar; de outro, [encontramos] as facilidades de uma economia de assistidos, quasi-ludica, fundada na subvenção, com alimentação e moradia a preços baixos, entradas para o teatro e para o cinema a preços reduzidos, etc. (Bourdieu, 1983, p. 113)

Estes são dois extremos de um espaço de possibilidades oferecidas aos jovens. Para o autor, a "situação de adolescente", subvencionada e assistida, decorre de sua existência "escolar", "estudantil", essa existência "em separado" que os coloca temporariamente (e socialmente) "fora do jogo". Bourdieu aponta ainda que é esta condição de 
apartação social temporária que permite ao jovem aquela sensação de “estranhamento" em relação às regras, normas e valores sociais já apontada pó Mannheim.

Mas há algumas distinções entre as perspectivas dos dois autores quanto a este ponto (além, claro, daquela fundamental que faz com que, em Mannheim, tenhamos o estudo das condiçóes que fazem da juventude um conjunto e, em Bourdieu, uma reflexão acerca das distinções fundamentais relativas a um grupo que apenas adquire certa homogeneidade quando situado no interior de determinada instituição). Se para Mannheim o "estrangeiramento" do jovem em relação à sociedade em que vive advém da própria condição juvenil, para Bourdieu o estranhamento das regras, normas e valores sociais é efeito da inserção escolar. Neste sentido, para este autor, escola "cria" juventude (ou cria as condiçôes para o exercício de uma forma particular de transição entre a infância e a maturidade, entendida de maneira geral como "juventude").

A preocupação com as clivagens que separam os jovens, em especial as diferenciações de classe, é uma marca da obra de Bourdieu, e suas considerações acerca da juventude não constituem exceção. Dessa forma, se em Mannheim temos a definição do que dá unidade à juventude, em Bourdieu (presente em sua instigação "juventude é apenas uma palavra") encontramos acento naquilo que a diferencia. Naquilo que a distingue. São duas abordagens diversas para o enfrentamento de uma questão semelhante: a juventude como posição social.

Para finalizar essa discussão, trazemos uma dupla de autores que, ao tratar juventude como posição social, ao mesmo tempo construída e desigual, acaba por forjar uma ferramenta importante e bastante operativa para "medirmos" o grau de separação entre as formas diversas de exercer a condição juvenil nas sociedades modernas: Mário Margulis e Marcelo Urresti.

Partindo do princípio de que as práticas e produções simbólicas legitimadas são uma construção da sociedade e que, portanto, as noções e categorias "essencializadas" e "naturalizadas" pelo senso comum devem ser permanentemente postas em causa, apontando ainda ser este o caso da noção de juventude, Mário e Urresti (1996) põem em ação diversas noções e categorias que tencionam a noção de 
Juventude, trabalho e escola: elementos para análise de uma posição social fecunda

juventude, oferecendo-nos ferramentas capazes de ampliar sua compreensão naquilo que envolve a diversidade e as desigualdades que marcam as formas de ser jovem.

Para eles, há uma espécie de base material, fundamento concreto da juventude. Este fundamento é a sua cronologia (objetiva, présocial, pré-biológica, física). Esta cronologia, porém, existe em sociedade. Está, portanto, investida de uma "forma" sociocultural (valorativa e estética). E é "vestida" desta forma que a juventude se faz "visível". É também desta forma que ela se constitui num "capital social".

O composto resultante é o corpo do jovem, que não é feito "só" de cronologia, pois esta, desprovida de expressão valorativa, sem cultura, é materialidade bruta, estatística. Por outro lado, esse corpo não pode ser visto apenas como "livre" expressão de cultura, porque cultura sem "cronologia" - base material - é algo vazio; simbolismo autóctone, culturalismo.

Os autores avançam sobre esse aparente impasse, propondo que pensemos a juventude como um período da vida em que se está de posse de um excedente temporal, tendo "mais possibilidade de ser jovem todo aquele que possua este capital temporal como condição geral”. Os autores chamam este excedente - disponibilidade para a vida - de "moratória vital”. ${ }^{1}$

Como já foi apontado, porém, esta potencialidade "energética" se realiza nas relações sociais. Ela se manifesta na sociedade e, ao fazêlo, sofre "mutação". Aqui, o exercício das possibilidades abertas pela moratória vital, esse excedente temporal e energético, vê alteradas sua capacidade de expressão e de realização, dependendo da posição social ocupada pelo sujeito.

Isso significa que não apenas as diferentes expressões juvenis serão objeto de processos diversos de legitimação e de hierarquização que as posicionarão em escala, de acordo com os espaços sociais de onde emanam, como também a possibilidade mesma de expressão (da "juventude") por parte dos jovens estará condicionada à posição social que estes ocupam. Estamos falando, aqui, de jovens com desiguais direitos de fazer uso e expressão de sua condiçãao juvenil. Jovens sem direito à juventude.

Moratória vital é, portanto, capital energético, valor de uso. É sobre esta moratória que se desenvolve o valor de troca: 
Isto é, a linguagem social que compatibiliza esta diferença energética num signo (capital simbólico) que permite sua intercambialidade, em uma abstração, e que permite, por sua vez, uma particular distribuição social, por classe, desse capital, em que jogam os interesses do "mercado". (Margulis \& Urresti, 1996, p. 23)

A possibilidade de apropriação (e, portanto, de uso) desse capital simbólico ("a juventude") está referida a outra "reserva", essa de caráter social, uma espécie de "crédito" que a sociedade, através de sua rede de instituições, oferece a alguns jovens. ${ }^{2}$ A esse crédito social, de caráter formativo, que garante, por hipótese, a reprodução da sociedade, Margulis e Urresti dão o nome de moratória social.

Moratória social faz referência, portanto, a um "tempo doado" pela sociedade para que seus jovens experimentem a condição adulta, permitindo-lhes então configurar trajetórias de inserção social com maior autonomia. A questão é que, em sociedade, esse tempo de experimentação varia com a condição social dos sujeitos, havendo casos em que a condição se alonga indefinidamente e outros em que esta não pode ser sequer experimentada.

Entendemos que a oferta de moratória está articulada a um número significativo de instituiçôes sociais responsáveis por sua realização: escola, universidade, Igreja, família, mas também partidos políticos, associações classistas, equipamentos e organizações culturais. Atualmente, novos elementos vêm se agregando às instituições mais tradicionais nos processos de socialização da juventude e permitindo uma experimentação mais autônoma da condição juvenil, entre estes os grupos de pares e as mídias eletrônicas, por exemplo.

De qualquer forma, mesmo que se admita este como um processo geral, é fato que as condições de uso destas redes de instituições não estão postas de maneira semelhante para todos numa mesma sociedade. É igualmente verdade que o grau de desigualdade na oferta desta rede de instituições varia de acordo com as marcas das desigualdades sociais.

Assim, experimentar a juventude, essa espécie de "aprendizado" ou, na melhor das hipóteses, de "reinvenção" da condição adulta, pode significar, neste país, a experimentação de vivências incomunicáveis por causa das distâncias sociais que estão na origem das mesmas: pelas instituiçóes que mobilizam, pelo grau de vulnerabilidade 
Juventude, trabalho e escola: elementos para análise de uma posição social fecunda

ou, ao contrário, de suporte social que comportam, pelos rituais que expressam, pelas expectativas que geram ou abortam e, finalmente, pelo grau de inserção social que anunciam. Dessa forma, estudar as desigualdades anunciadas nas maneiras de se experimentar a juventude pode significar estudar uma das dimensões mais fundamentais das formas de desigualdade postas para a nossa sociedade.

Moratória é, portanto, uma postergação sustentada pela sociedade e por suas instituições, variável em termos de alcance na sociedade, de tempo de duração e do conjunto das instituições e dos investimentos públicos envolvidos em sua realização. Mas há ambiguidade nesta postergação. E é novamente a Bourdieu (1983) a quem recorreremos, como auxílio para desenvolvermos a questão.

Já demonstramos que, para o autor, ser jovem é ocupar uma posição singular, possibilitada pela escola nas sociedades modernas e urbanas, que aparta o jovem da sociedade, livrando-o temporariamente das responsabilidades da vida adulta. Ocorre, porém, que ao fazê-lo, este é segregado também dos "jogos sociais de poder”, postergando sua autonomia (este modelo, de certa forma, garante que as gerações precedentes controlem, parcialmente, os mecanismos de transição para a vida adulta).

Para Bourdieu, essa postergação constitui-se de uma combinação complexa de autonomia e tutela nas relações para com o mundo adulto. Essa espécie de postergação da vida adulta é, portanto, ambígua. Tem, por um lado, em nossas sociedades, um teor de investimento na autonomia futura. É necessário lembrarmos, porém, que essa condição de "suspensão do jogo" não está garantida, de forma idêntica, para todos os jovens em nossas sociedades. Na verdade, ela se diferencia não só em termos do grau de suspensão, e do prazo de sua vigência, mas, principalmente, da concentração de capital, acumulado e disponível para ingresso na vida adulta.

Assim, se alguns jovens terão uma transição que os colocarão em situação de total disponibilidade para, na convivência com seus pares, experimentarem didaticamente e escolherem, criteriosamente, os modelos de autonomia adulta que os "espera" (mesmo que, hoje, essas escolhas envolvam menos garantias do que já envolveram); para outros, porém, o processo se encurta. Partem quase que imediatamente da adolescência para um mundo do trabalho, em que a autonomia fica 
sempre submetida (e fica também submetida futuramente. Aqui, os constrangimentos de geração encontram os constrangimentos próprios da reprodução das classes). Nesse sentido, é necessário diferenciar autonomia de classe de autonomia de geração, para entendermos como ambas se cruzam na constituição de autonomias desiguais nos processos de transição para a vida adulta (e mesmo que não seja nosso objetivo, no escopo desta análise, responder a esta questão, é necessário mantermos no horizonte a pergunta: que situações constrangem os sujeitos desigualmente posicionados em termos sociais em processo de transição para a vida adulta?).

Munidos da noção de que juventude se constitui numa posição social, liminar no conjunto (na emancipação parcial da socialização primária referenciada na família e na comunidade para inserção em novas instituições de socialização, com maior ou menor disponibilidade para a construção de sociabilidades coletivas e mais autônomas), mas atravessada pelas divisões que marcam o conjunto da sociedade (tornando essa posição como uma experiência variável e desigual), buscamos, a partir do ano de 2009, construir um projeto de pesquisa que permitisse, tomando como ponto de partida os sujeitos participantes de determinado programa de preparação para o trabalho, aprofundarmos nossos conhecimentos acerca dos modos de viver o processo de transição para a vida adulta, colocando em relação escola, trabalho e território, neste processo.

Um estudo de caso: a juventude como posição analítica e a importância relativa da escola média recém expandida no Brasil

Para tratarmos da questão, trazemos aqui, portanto, os primeiros resultados de uma pesquisa em andamento desde setembro de 2009, que busca compreender as regularidades e as singularidades que marcam as trajetórias de escolarização e de trabalho dos jovens moradores de São Gonçalo, cidade periférica do leste metropolitano do Rio de Janeiro. Nela tentamos compreender os possíveis nexos entre os modos de escolarização abertos no processo de expansão da escola e os modos de inserção no mundo do trabalho abertos pela expansão da economia local, assim como suas possíveis expressões territoriais.

A partir da caracterização da história da cidade e do levantamento da distribuição de equipamentos e de bens de consumo coletivo em 
Juventude, trabalho e escola: elementos para análise de uma posição social fecunda

cada um de seus cinco distritos, conseguimos construir um mapeamento que, ainda preliminar, permite-nos comparar as condições de vida em cada uma das regióes administrativas da cidade.

A partir daí, buscamos, junto ao cadastro do programa Projovem Trabalhador do município, o conjunto de jovens que, moradores da cidade, saindo do ensino médio e em busca de trabalho e de qualificação profissional, constituíssem o grupo que nos permitisse acesso às respostas que buscávamos em nossa investigação.

As análises constantes deste texto são frutos dos dados referentes ao cadastro do programa Projovem Trabalhador (que, no caso de São Gonçalo, contava com 6.473 jovens de ambos os sexos) e dos resultados de questionários fechados aplicados a 5\% da amostra, obedecendo a um plano de aplicação que buscava captar a diversidade de jovens matriculados a partir da variedade de cursos oferecidos, da escolaridade mínima necessária para inscrição nos mesmos e dos locais de oferta. Se nossos dados, portanto, ainda não permitem conclusōes definitivas, eles abrem caminho, certamente, para a constituição de algumas hipóteses bastante fecundas.

\section{Uma brevíssima caracterização do campo da pesquisa: a cidade de São Gonçalo}

Pouco vigorosa em termos industriais (no quadro das demais cidades médias metropolitanas do Rio de Janeiro), São Gonçalo será possivelmente beneficiada pela implantação de um polo petroquímico em região próxima. Sua economia, atualmente, tem importante participação do setor de serviços, com forte dependência das economias de Niterói e do Rio de Janeiro. A cidade encontra-se subdividida em cinco distritos: Neves, São Gonçalo, Sete Pontes, Monjolos e Ipiíba.

A relativa melhoria da situação econômica vivida nos últimos anos e as promessas de crescimento trazidas pela construção do polo, porém, não vêm sendo traduzidas na melhoria de seus serviços de infraestrutura urbana. Tomando apenas os dados referentes ao abastecimento de água por rede geral e ao percentual de domicílios ligados à rede geral de esgotamento sanitário, verifica-se que São Gonçalo (assim como os demais municípios do leste metropolitano do Rio de Janeiro, 
com exceção talvez de Niterói) não tem sido capaz de transformar seu crescimento econômico em benefícios para a população habitante.

O modo de urbanização crescente e polarizada, que implicou, num primeiro momento, melhorias concentradas em algumas de suas regiões (em especial o Distrito de Neves), não teve contrapartida num plano que estendesse os benefícios às demais regiões, o que contribuiu para as desigualdades presentes entre seus distritos. Mesmo contando com indicadores que apontam para precários serviços de infraestrutura urbana em todos os seus distritos, há concentração destes nos dois distritos mais equipados (Neves e São Gonçalo) e déficit significativo em dois outros (Monjolo e Ipiúba). Isso nos permite concluir que, se por um lado, São Gonçalo é desigual mesmo na distribuição de seus parcos recursos, por outro lado, mesmo nas faixas sociais mais vulneráveis, encontraremos nuances significativas em termos de condições de vida. Como tais nuances impactam os processos de transição para a vida adulta?

\section{Uma breve caracterização dos jovens matriculados no programa ${ }^{3}$}

Do total de jovens, 69\% dos matriculados pertencem ao sexo feminino. Quanto à cor da pele, as proporções distribuem-se de maneira semelhante para homens e mulheres: 34\% de brancos; $22 \%$ de negros e 44\% de pardos. Quanto à escolaridade, 55\% dos jovens matriculados têm ensino médio completo; $20 \%$ têm ensino médio incompleto; $10 \%$ têm ensino fundamental completo e $7 \%$ têm ensino fundamental incompleto (o grupo com ensino fundamental completo e incompleto, como já era de esperar, acumula percentuais mais altos nas mais baixas faixas de renda - aqueles que acumulam valores de renda familiar não superiores a um salário mínimo). Os percentuais de jovens com ensino técnico e superior incompleto não são significativos.

Do conjunto, $11,5 \%$ dos jovens encontram-se na faixa de renda familiar de até meio salário mínimo, $31 \%$ estão na faixa que vai de meio a um salário mínimo, $44,5 \%$ estão na faixa entre um e dois salários mínimos, $9,5 \%$ estão na faixa entre dois e cinco salários mínimos e apenas $3,5 \%$ estão na faixa entre cinco e dez salários mínimos. 
Juventude, trabalho e escola: elementos para análise de uma posição social fecunda

As mulheres estão mais representadas nas faixas etárias mais altas cobertas pelo programa (os rapazes são predominantes nas faixas etárias mais baixas) e têm menos acesso a e-mail (ao contrário dos rapazes).

Quando cruzamos os dados sobre a renda familiar com a variável sexo, percebemos que se a predominância e a importância relativa da faixa que agrupa aqueles que têm renda familiar de um a dois salários mínimos são semelhantes para os dois sexos, a situação é outra quando comparamos os percentuais presentes nas faixas de renda das "extremidades". Há maior percentual de mulheres nas mais baixas faixas de renda e menor percentual destas nas faixas de renda mais altas. O contrário acontece com os rapazes: estão mais representados nas faixas mais altas e menos representados nas faixas mais baixas.

Quando relacionamos renda e distrito de moradia, percebemos que, apesar de operarem com faixas percentuais mais ou menos próximas, os distritos mais bem providos (em termos de equipamentos públicos de consumo coletivo) são Neves e São Gonçalo e estes apresentam menores percentuais das mais baixas faixas de renda e maiores percentuais das mais altas faixas de rendimento. Essas diferenças ficam ainda mais claras quando tomamos os dois distritos mais distantes dos dois primeiros em termos de provimento de equipamentos: os distritos de Monjolos e de Ipiíba.

\section{Primeiras constataçôes provenientes da análise dos questionários}

Com base no quadro formado pela análise do cadastro, propusemo-nos, com o intuito de aprofundarmos qualitativamente algumas questōes de pesquisa, construir um questionário fechado para captação dos elementos fundamentais das trajetórias escolares, das experiências de trabalho e do tipo de enraizamento dos jovens no território.

Primeiramente, é importante esclarecer que selecionamos para esta apresentação os questionários respondidos pelos jovens com ensino médio completo, residentes nos distritos mais extremos em termos de condiçōes de vida e de provimentos de equipamentos e bens públicos. De um lado, Neves (o distrito mais antigo, planejado e provido da cidade) e, de outro, os distritos de Monjolos e de Ipiíba, que, como já sabemos, são aqueles que concentram as condiçôes mais adversas na cidade. 
Constatamos, em primeiro lugar, que as mulheres, como nos mostram os dados do cadastro, não são apenas predominantes numericamernte. Elas são também mais velhas ( 24 a 29 anos), casadas ou solteiras, em busca de reinserção no mercado de trabalho. É significativo também o número de mulheres mais velhas e casadas que buscam no programa sua primeira inserção no mercado de trabalho.

Os mais jovens, tanto do sexo feminino quanto do sexo masculino, também estabelecem um "tipo" no conjunto. Com idades que variam de 18 a 20 anos e ensino médio completo feito sem reprovações, são jovens que, apesar de nunca terem trabalhado, ou de o terem feito por períodos muito curtos, acumulam uma infinidade de cursos de preparação/qualificação para o trabalho, ${ }^{4}$ e que nos casos mais promissores agregam um conjunto de funçóes que caracterizam uma área de formação.

Mesmo trabalhando com um grupo relativamente homogêneo (todos com ensino médio completo, matriculados em cursos de preparação/ingresso no mundo do trabalho, moradores de cidade situada na periferia da metrópole carioca), foi possível a captação de nuances importantes para a investigação. Como era de se esperar, os jovens das regiôes mais providas eram também aqueles de maior renda, os que frequentavam as escolas públicas de referência na região, os que conseguiam articular suas poucas e efêmeras experiências de trabalho com cursos de capacitação que permitiam a configuração de uma "área de atuação". Estes eram também os jovens "mais novos", que não apenas afirmavam circular nos núcleos mais dinâmicos de cidades como Rio de Janeiro e Niterói, como também indicavam querer ampliar seu acesso a tais núcleos.

Em contrapartida, do conjunto dos jovens matriculados no programa, aqueles residentes nas regióes mais precariamente providas de serviços e equipamentos públicos (os distritos de Monjolos e Ipiíba) foram também os que acumularam as maiores frequências de escolarizaçôes noturnas, alguns com históricos de repetências, em escolas locais (não nucleares) e menos equipadas. As experiências de trabalho eram reduzidas e restritas, assim como os relatos dos cursos de qualificação realizados. Entre estes jovens também foram mais frequentes os relatos de trabalhos manuais e domésticos. As experiências de trabalho e de escolarização eram mais restritas em Ipiíba e mais variadas em Monjolos. 
Monjolos e Ipiíba são os dois distritos com menor presença de equipamentos e bens públicos, num município de precária provisão destes. Do universo de jovens estudado, os moradores destes distritos foram os que apresentaram maior frequência nas mais baixas faixas de renda. A renda apresentada era menor em Monjolos e maior em Ipiíba. Em Monjolos, a vida é mais precária do que em Ipiíba, que é mais isolado (menos central e pouco provido em termos de transporte coletivo) do que Monjolos.

A frequência com que os jovens moradores de Monjolos e Ipiíba têm acesso aos núcleos centrais do Rio de Janeiro e Niterói e, às vezes, até do centro de São Gonçalo é baixa (relativamente mais baixa em Ipiíba do que em Monjolos). Contudo, no desejo de ampliação de circulação, os jovens moradores dos dois distritos se afastam: se este desejo está presente em Monjolos, ele não se apresenta em Ipiíba.

\section{Conclusão}

Estivemos, num primeiro momento, construindo a ideia da fecundidade de trabalharmos com juventude como posição social, ao mesmo tempo diversa e desigual nas sociedades de classes, posição esta caracterizada, nos meios urbanos, pela postergação das responsabilidades sociais (incluindo o trabalho), na constituição de um período de "formação" para inserção no mundo adulto.

Mas operar a juventude como posição significa construir esta posição no processo de investigação. Como na física, na sociologia bourdiana, uma posição social pode ser feita da conjugação das posições parciais ocupadas por sujeitos em determinada instituição (como ao estudarmos, por exemplo, as trajetórias de escolarização de jovens), ou tomando os sujeitos como base e referência, pela construção de suas posições diferentes a partir da relação que mantêm para com mais de uma instituição.

Tomar os jovens como eixo, investigar suas condiçōes de vida, suas trajetórias escolares, sua experiência de trabalho, seu território de moradia, seu horizonte de circulação, permitiu-nos algumas constatações. Recortaremos aqui apenas aquelas pertinentes à temática deste texto.

De alguma forma, escolas nucleares, equipadas (ou ao menos com instalaçōes estruturais que, mesmo momentaneamente desativadas, 
permitem a reivindicação de equipamentos, tais como laboratórios científicos, quadras de esportes, espaços para apresentações artísticas), relacionavam-se nos dados colhidos a experiências mais complexas de inserção no mundo do trabalho, compostas de trabalho fugaz e não registrado no terciário e frequência a cursos de capacitação com a busca de constituição de uma área de atuação laboral. Os sujeitos que mais frequentemente estavam associados a este tipo de trajetória eram os mais jovens, com predomínio dos do sexo masculino, moradores dos distritos mais providos em termos de equipamentos e serviços em todo o município.

Estudar (especificamente fazer ensino médio) em escolas locais, pequenas, noturnas, pouco equipadas (algumas delas de ensino fundamental diurno "emprestadas" ao ensino médio noturno) relacionava-se a experiências de trabalhos manuais e domésticos (muitas vezes concomitante com a escolarização) ou à ausência completa de qualquer experiência laboral, a poucos ou nenhum curso de capacitação para o trabalho.

As experiências diversas relacionam-se, por sua vez, a diferentes horizontes de circulação dos jovens pelos núcleos urbanos mais próximos, de tal forma que as experiências mais complexas (de escolarização, de trabalho, de constituição de uma área de atuação profissional) corresponderam, mais frequentemente, ao desejo de expansão do horizonte de circulação. Ao contrário, experiências restritas (de escolarização e de trabalho), aliadas ao isolamento territorial, corresponderam a restritos horizontes de circulação.

Finalmente, esse estudo nos permitiu a construção de novas e fecundas hipóteses para trabalhos futuros: em primeiro lugar, ele nos mostra ser possível distinguir nuances dentro dos grupos de jovens de precária inserção social, naquilo que toca suas experiências de trabalho e de suas trajetórias escolares, ao tomarmos o tipo de território que habitam como eixo de análise em composição com os dois demais; em segundo lugar, nos abriu importante eixo para estudos referentes às novas desigualdades criadas pela expansão da escola, em especial na expansão do ensino médio; em terceiro lugar, nos possibilitou mensurar a posição relativa da escola nos processos de transição para a vida adulta, especialmente para jovens pobres moradores de periferia urbana em expansão; por fim, nos permitiu interrogar, tornando mais complexa, a 
Juventude, trabalho e escola: elementos para análise de uma posição social fecunda

proposição de que a expansão da escola, por si só, amplia as possibilidades de experimentação da condição juvenil. É importante afirmar aqui que estas considerações só foram possíveis quando decidimos tomar os jovens como eixos da análise, e as posiçôes diferenciais ocupadas por estes como eixos de nossa argumentação.

Há muito que aprendemos com Bourdieu que a expansão escolar não tem apenas efeito sobre os processos de certificação escolar, com alteração dos números e do valor dos certificados escolares. Sabemos também que a frequência à escola afeta o conjunto de disposiçôes sociais acumuladas pelos sujeitos, ampliando suas expectativas de inserção social. Se a escola "cria" juventude pela postergação da assunção das responsabilidades sociais por parte dos jovens e, ao mesmo tempo, pela geração e ampliação de suas expectativas de inserção, então, que tipo de "postergação" se cria na expansão da escola média?

São essas possibilidades que, mesmo em estudos preliminares, nos instigam a aprofundar nossas investigações, abrindo, quem sabe, novos flancos para a pesquisa acerca das relaçôes entre juventude e escola em nosso país.

\section{Notas}

1. Poderíamos interpretar a "moratória vital" de Margulis e Urresti como a "reserva vital" de Mannheim captada pela perspectiva dos sujeitos? "Moratória vital" seria a realização subjetiva da "reserva vital" social de Mannheim?

2. A oferta mais ou menos generalizada deste crédito varia com o grau de desigualdade da sociedade. Quanto mais desigual é a sociedade, mais restrita é a "distribuição" deste crédito social. "Diante disso, sociedade de classes, diferenças econômicas, sociais, políticas, étnicas, raciais, migratórias, marcam profundas desigualdades na distribuição de recursos, com a qual a natureza mesma da condição de jovem em cada setor social se altera. É nesse sentido que Silvia Sigal afirma que, na América Latina, diferente da Europa onde seria mais ampla, a 'juventude' está quase que reservada para os setores médio e alto, que podem ascender à educação superior e 'a moratória em toda plenitude do termo" (Margulis \& Urresti, 1996, p. 14).

3. A caracterização a seguir foi feita a partir do cruzamento dos dados colhidos no cadastro do programa em São Gonçalo, em 2009.

4. Nestes cursos também já é possível perceber “tipos” diferentes. Percebemos que há os cursos que chamaremos de "básicos", como inglês, espanhol, cursos de informática, digitação, e cursos que chamaremos de "capacitação" para atividades mais dirigidas. 


\section{Referências}

BOURDIEU, P. A juventude é apenas uma palavra. In: Bourdieu, P. Questôes de sociologia. Rio de Janeiro: Marco Zero, 1983. p. 112-122. LENOIR, R. Iniciação à prática sociológica. Petrópolis: Vozes, 1998. MANNHEIM, K. O problema da juventude na sociedade moderna. In: Brito, S. Sociologia da juventude I. Rio de Janeiro: Zahar, 1968. p. 69-95.

MARGULIS, M.; URRESTI, M. Juventud es más que una palabra: ensaios sobre cultura e juventud. Buenos Aires: Biblos, 1996.

PEREGRINO, M. Juventude e trabalho em tempos de expansão da escola. Relatório de finalização de pós-doutorado, Universidade de São Paulo, São Paulo, 2010.

Recebido em 24 de março de 2011. Aprovado em 28 de abril de 2011. 